\title{
Varieties of Probability in Clinical Diagnosis
}

\section{Pierdaniele Giaretta}

Department of Philosophy, Sociology, Pedagogy and Applied Psychology, University of Padua Piazza Capitaniato 3, Padua 35139, Italy

E-mail: pierdaniele.giaretta@unipd.it

\section{Daniele Chiffi}

Ragnar Nurkse Department of Innovation and Governance, Tallinn University of Technology

Akadeemia tee 3 , Tallinn 12618, Estonia

E-mail: chiffidaniele@gmail.com

\begin{abstract}
In clinical diagnosis, both causal attribution and the interaction between different types of probability may take place. We deal with a hypothetical, but quite realistic, clinical case and go through various idealized ways in which the case can be framed. In the diverse scenarios linked to our proposed case, the possibility of causal attributions will be taken into account and each one of them will correspond to a distinct role of probabilistic evaluation. For some of these scenarios, it will be necessary to comply with certain requirements such as the construction of a specific partition that serves as a point of reference for the diagnostic analysis. The interaction between probabilities occuring within these scenarios will be critically investigated, as it may shed light on some causality claims in clinical diagnosis.
\end{abstract}

Keywords: causality, clinical reasoning, diagnosis, probability 


\section{Introduction}

Some Italian and Polish methodologists and philosophers of medicine highlighted the distinction between the research activity geared towards broadening medical knowledge-possibly leading to the identification of new diseases or the discovery of new biomedical processes - and that which is aimed at recognizing the disease or the pathological process affecting a particular individual. ${ }^{1}$

According to Augusto Murri (1841-1932), the accelerated progress of theoretical knowledge in medicine has contributed to a widening gap between clinical activity and pathological research. He argued that the activity of the clinician was very different from that of the pathologist. While the latter seeks to solve new open problems, attempts to point out new relationships between phenomena, and ends up viewing diseases as abstract entities, the former only needs to re-cognize (ri-conoscere, in Italian) the disease; that is to say, to place the phenomena occurring in a patient within the context of the already codified knowledge. Murri was convinced that the clinician's task of re-cognizing might be even more challenging than that of the researcher. While the latter, in fact, can isolate a problem from contour factors, and tackle the problem with the help of an experiment, the clinician has to consider and dissect the entire set of phenomena that is present in his/her patient.

Likewise, Giovanni Federspil (1938-2010) and Cesare Scandellari (1933- ) endorse Murri's distinction of the two main medical fields: the pathological and the clinical. Also according to them the objectives and methods of pathological research vary from those of clinical activity, but they never affirm that the biomedical knowledge of the pathologist is irrelevant to solving clinical problems.

Tytus Chalubinski (1820-1889), founder the Polish School of Philosophy of Medicine, along with his colleague Edmund Biernacki (1866-1911) argued that the clinical method must be based on a holistic approach and be directed towards the care of the symptoms. According to Biernacki, in particular, the clinician's work does not require deep understanding of the phenomena that occur in the human body. He distinguishes the knowledge, often only partial, of the disease from its recognition, and admits that the progress in the understanding of diseases has refined the diagnostic possibilities, but believes that "knowledge about the diseases and therapeutics are independent of one another, and in fact,

\footnotetext{
See Murri, 1972; 2004; Antiseri, 1981; Scandellari \& Federspil, 1985; Federspil, 2004; 2010;
} Scandellari, 2010; and Löwy, 1991. 
they exist in the doctor's mind as two different kinds of knowledge" (Biernacki, 1991, p. 57). Contrary to what most doctors believe, a diagnosis is not necessary for the treatment of diseases. ${ }^{2}$ However, Wladyslaw Bieganski (1857-1917), another member of the same school, believes that the clinician cannot renounce establishing what the nature of the disease affecting the patient is and that the therapeutic indications should be grounded on this judgment.

The present paper builds upon the point of view of the aforementioned methodologists and philosophers of medicine, according to which clinical activity has its own methods and does not intend —at least as its primary goalto increase the knowledge of pathological science, even if it presupposes the codified knowledge of this science in order to make the correct diagnosis and then proceed to therapeutic indications. ${ }^{3}$

In particular, we will assume that, in certain cases, the clinician avails himself/ herself of the already established causal knowledge, sometimes expressed by means of sentences of the type, 'the phenomena X may be caused by $Y$ ', or 'the phenomena $\mathrm{X}$ are sometimes/often/always caused by $\mathrm{Y}$ '. We also argue, as is implicitly assumed in clinical practice, that nothing prevents in talking about the probability that the phenomena $\mathrm{X}$ are caused by $\mathrm{Y}$. Such talk merely needs to be clarified.

The knowledge of the causes constitutes a part of the pathogenetic knowledge and certainly contributes towards justifying the diagnosis. However, this knowledge is not always available. Johansson and Lynøe distinguish between the knowledge of the mechanisms "that explain how a certain event can give rise to a certain effect" (Johansson \& Lynøe, 2008, p. 179) and the correlation knowledge that provides "statistical associations between diseases and variables such as age, sex, profession, home environment, lifestyle, exposure to chemicals, etc." (Johansson \& Lynøe, 2008, p. 181). These two types of knowledge are interconnected:

mechanism knowledge and correlation knowledge cannot only complement each other, but also interact in a way that makes both of them grow faster than they would on their own (Johansson \& Lynøe, 2008, p. 182).

As suggested by Johansson and Lynøe, even correlation knowledge, when appropriately improved, can help reach a diagnostic judgment.

2 Diagnostic reasoning does not occur just in medicine but also in other clinical disciplines such as nursing (see, for instance, Zanotti \& Chiffi, 2015) and other sciences.

3 The Polish Bieganski, who also argues for the need to provide a diagnosis, and who connects diagnosis and therapy, is rather concerned with emphasizing the unity of medicine than with the diversity of tasks pertaining to pathology and clinical medicine. 
Whatever type of knowledge the clinician refers to, it is unavoidable for him/ her to make probabilistic assessments. Additionally, it is unrealistic to expect that his/her assessments do not represent a personal opinion. It is reasonable, instead, to expect and to require that the clinician takes into account the relevant statistical probabilities. When doing so, the clinician may draw inferencescalled 'cross-over probabilistic inferences' by Johansson and Lynøe-in which "the premises are frequency-objective (ontological) statements and the conclusion is a subjective (epistemological) probability statement" (Johansson \& Lynøe, 2008, pp. 139-140). We agree entirely with this, but we would also like to add that the cross-over between different kinds of probabilities does not have only an inferential form. Below, we will provide a more general analysis of this.

In clinical diagnosis, both the process of causal attribution and the cross-over between probabilities may take place. We will deal with a hypothetical, yet quite realistic, clinical case and will propose different idealized scenarios where the case can be applied. The possibility of causal attributions will gradually decrease and the role of the probabilistic evaluations will change. On some of these idealized scenarios, special requirements need to be satisfied by the partition providing the point of reference for the diagnostic research. The cross-over between probabilities occurs in these framings as an important, not negligible aspect.

\section{The clinical case: first version}

Suppose we know that a given pathogen $g$ rarely causes disease $f$. Doctors tend to express themselves in this way, without offering any overarching analysis about what it means to say that something never/rarely/ ... /often/always causes something else. Let us call $\mathrm{G}$ the exposure to $g$ and $\mathrm{F}$ the patient coming down with the disease $f$. As many doctors would do, we assume, moreover, that the fact that $g$ rarely causes $f$ implies that, with respect to the reference population, the statistical probability $\mathrm{P}(\mathrm{F} / \mathrm{G})$ is low or very low. How can one nevertheless say that, in certain specific circumstances, the event $\mathrm{F}$ is due to the event G? If $a$ is the individual in question, how can one, in other words, say that in the given circumstances $\mathrm{Fa}$ took place ${ }^{4}$ because of $\mathrm{Ga}$ ? Both $\mathrm{Fa}$ and $\mathrm{Ga}$ took place, but obviously this is not enough to justify the assertion ' $F a$ because $G a$ ', where the 'why' has causal meaning. May we think that in the circumstances in

4 Here, and in the following, we adopt this shorter way of speaking instead of referring, more correctly, to the event the sentence is about. 
which the event $F a$ has taken place, including the previous occurrence of $G a$, the probability of $F a$ given $G a$, understood as a non-statistical probability, is much higher than $\mathrm{P}(\mathrm{F} / \mathrm{G})$ ? Do we thus have an example of a cross-over probability?

Consider the following case. We know that the probability of a person who has eaten shellfish developing a glottal oedema is low, and we also know that James has eaten shellfish. We observe that James has developed a glottal oedema. The glottal oedema is "a rare pathological condition, allergic in nature that occurs shortly after the contact between an allergen and a sensitive subject, and admits only a few possible causes among which there is certainly the ingestion of shellfish" (Federspil, 2005, p. 76) ${ }^{5}$. Knowing that in the few hours before the onset of the glottal oedema James had not come into contact with other substances possibly containing allergens, a clinician would conclude that, with high probability, James developed the oedema of the glottis due to the ingestion of shellfish.

From the logical point of view, the clinician makes an inference based on the premises which he recognizes as true and the inference leads him/her to recognize the truth of the conclusion that is inferred. What are the premises of the inference? If we include among them the general relevant knowledge concerning the glottal oedema, we have:

(A) The probability that a person who has eaten shellfish shortly afterwards will develop a glottal oedema is low.

(B) James has eaten shellfish.

$\left(B_{1}\right) \quad J a m e s$ has a glottal oedema.

$\left(\mathrm{B}_{2}\right) \quad$ The glottal oedema has an allergic cause.

$\left(\mathrm{B}_{3}\right) \quad$ After the ingestion of shellfish, and before the onset of the glottal oedema, James did not come into contact with known allergens other than those contained in shellfish and a possible previous contact with a known allergen could not have caused the oedema.

$\left(\mathrm{B}_{4}\right)$ The glottal oedema appeared shortly after the ingestion of shellfish.

The conclusion that is considered as being very likely is the following:

(C) The cause of James' glottal oedema was the ingestion of shellfish.

5 Glottal oedema, better known nowadays as laryngeal oedema, is an "abnormal accumulation of fluid in tissues of any part of the larynx, commonly associated with laryngeal injuries and allergic reactions" (MeSH (Medical Subject Headings), 2018). 
The conclusion (C) actually appears very likely, despite the premise (A). Consequently, one might have the impression that an event, that is, James' glottal oedema, which according to (A) is unlikely given the ingestion of shellfish, appears certainly, or almost certainly to be caused by the ingestion of shellfish. Suppose that (A) is asserted on the base of a statistical investigation. Do we have a transition from a low statistical probability to a high probability of another kind?

We cannot give an accurate response without first observing that the ingestion of shellfish, which is given in (A) as the condition of a conditional probability, is alleged as something that happened to James and is then integrated with other information, including a specific example of the type of conditioned event, that is, James' glottal oedema. If we keep on talking in terms of conditional probability, we might be tempted to say that the supposed statistical probability $P(F / G)$ has given way to the probability of $F a$ given $G a$ and other information. There seems to be a transition from a statistical probability into a different kind of probability, though it should be noted that the transition is made while changing the content of the conditional probability.

The probabilistic analysis of the inference should be carried out in detail, but before doing so, it is worth pointing out that this type of analysis could be avoided, or brought about in a special way, if, after all the assumptions are made explicit, the inference ends up having a deductive nature.

Suppose it is considered obvious that

$\left(C_{1}\right)$ The absence of contact with allergens other than those contained in shellfish necessarily implies that none of them can have caused James' oedema.

Therefore, the falsity of the conclusion (C) is only possible, despite the truth of the premises $(\mathrm{B})-\left(\mathrm{B}_{4}\right)$, if one admits to the possibility that James' oedema depends on an allergen, which is unknown to us but which he came into contact with. In fact, from $\left(B_{1}\right)$ and $\left(B_{2}\right)$ it follows that the oedema of the glottis is only due to the action of an allergen; $\left(\mathrm{B}_{3}\right)$ states that shellfish contain the only known allergens James had contact with and which could have caused the oedema; and $\left(\mathrm{B}_{4}\right)$ states that the time between the ingestion of shellfish and the appearance of the glottal oedema was short, thus seeming to exclude-with high probability, but still in a way that is difficult to determine-that James could have come into contact with an unknown allergen such as to cause the oedema of his glottis. If this possibility is ruled out, (A) does not seem to have any role in the 
justification of $(\mathrm{C})$; thus, we can share Federspil's statement that "the conclusion is not based on the probability inherent in the law invoked" (Federspil, 2005, p. 76). ${ }^{6}$ Assuming that

$\left(\mathrm{C}_{2}\right) \quad$ James did not come into contact with any unknown allergen

we can point out that the piece of reasoning that was implicitly carried out appears to be deductive in nature. ${ }^{7}$

Of course, being able to reach a diagnostic conclusion by deductive inference does not guarantee the certainty of the conclusion. The conclusion of a deductive inference is certain if all of its premises are certain. Since this is not always the case, then neither can the conclusion gained through deductive reasoning always be certain. The case of premises not all being certain is quite common, but we cannot always notice the non-certainty of a premise. For example, it may be difficult to notice that in the deductive inference from $(B)-\left(B_{3}\right)$ and $\left(\mathrm{C}_{1}\right)-\left(\mathrm{C}_{2}\right)$ to $(\mathrm{C})$. Consider, in particular, the premises $\left(\mathrm{B}_{2}\right),\left(\mathrm{B}_{3}\right)$ and $\left(\mathrm{C}_{2}\right) .\left(\mathrm{B}_{2}\right)$ is a general statement concerning the cases of glottal oedema. Unless it is a part of the definition of a glottal oedema that its only possible causes are allergens, it cannot be excluded that there might be cases of this disease that do not have an allergic cause. Concerning $\left(\mathrm{B}_{3}\right)$, its reliability depends, among other things, on an investigation based on indirect observations, which were not made by the clinician but were reported to him, and which might be insufficient to exclude contact with other known allergens. $\left(\mathrm{C}_{2}\right)$ appears to be plausible, given the breadth of available knowledge about the possible allergens, but it obviously cannot be accounted for as certain.

If the uncertainty of a sentence $s$ is defined as $1-\operatorname{prob}(s)$, where 'prob' is an appropriate notion of the probability for sentences, we know that the uncertainty of a deductive conclusion does not exceed the total uncertainty of the premises, given by the sum of the uncertainties of the individual premises. In short, the uncertainty does not increase when validly inferring the conclusion. It can remain the same if the premises are consistent and all of them are essential for the validity of the deductive conclusion (Adams, 1975, 1998; Hájek, 2001). Consequently, in general, a deductive conclusion is less uncertain the less uncertain its premises are. It follows that assumptions that are more or less plausible (though not

6 There is a clear similarity between the case described by Federspil and the famous case of paresis due to syphilis adduced by Scriven (1959) to show that the causal attribution does not presuppose the high predictability of the caused effect.

7 Note that $\left(\mathrm{C}_{2}\right)$ can be suggested, of course not justified, by $\left(\mathrm{B}_{4}\right)$, and bereaves $\left(\mathrm{B}_{4}\right)$ of any role from the deductive point of view. 
certain), and that are too often taken for granted, may give the conclusion a degree of uncertainty that is too high compared to what is reasonably required for a clinical diagnosis and a choice of therapy.

However, is it adequate to define the uncertainty of a sentence $s$ as 1 -prob $(s)$ ? For the sake of argument, let us assume that it is, even if in the case under inspection, the probability concerns (also) sentences stating relations of causation, which is knowingly a complex and controversial issue. We agree that it is not clearly evident how to find a way to assign a probabilistic value to a statement of causation such as (C). An objective sense can be suggested by the fact that an allergen acts only under certain conditions, so that one might think to look for the percentage of the cases where such conditions are satisfied among the cases of contact with the allergen. On the other hand, the fact that these conditions are generally not known, or cannot be ascertained, seems to give room for the application of a subjective-epistemic notion of probability.

At any rate, it has to be kept in mind that the clinician has to express himself/ herself about particular cases on the basis of what he/she believes, and what he/she believes depends on his/her expertise and scientific background. Thus, it seems only natural to interpret the probabilistic assessments of the clinician about a particular case in an epistemic-subjective sense, as confidence levels based on personal opinions and knowledge. This calls for the question of how should the clinician be influenced by the available 'objective' scientific and statistical knowledge. It is a difficult and complex problem, which we will try to deal with in the next sections.

\section{The clinical case: second version}

Suppose that the clinician does not have any doubt about the allergic nature of the glottal oedema, hence he/she accepts $\left(\mathrm{B}_{2}\right)$, but he/she is not willing to hold $\left(\mathrm{B}_{3}\right)$ (after the ingestion of shellfish, and before the onset of the glottal oedema, James did not come into contact with known allergens other than those contained in shellfish, and a possible previous contact with a known allergen could not have caused the oedema) because he/she is not sure of the reliability of the investigation that was carried out to establish $\left(\mathrm{B}_{3}\right)$. The clinician might even doubt that the particular piece of shellfish eaten by James contained any allergens. The deduction of $(\mathrm{C})$ is no longer possible, thus the possibility of 
evaluating the probability of $(\mathrm{C})$ based on how the uncertainty of the premises is transmitted to the conclusion through deductions, is no longer available.

Can the clinician calculate the probability of (C) in a different way? Let us observe at the outset that the problem is not to determine how high the conditional probability is that James will have an oedema of the glottis given that he has ingested shellfish. When identified with the statistical probability of a glottal oedema given the ingestion of shellfish, this probability is low and, in any case, cannot in itself adequately represent a relation of causation. On the other hand, if it is assumed - from a Bayesian point of view—-that both James' glottal oedema and his previous ingestion of shellfish are acquired as entirely certain information, then the probability of each one of the two events is to be updated to 1 and, therefore, even the conditional probability of the former event given the latter is to be updated to 1 .

One might even decide to disregard any understanding of the relation of causation and may simply say that the statement (C) is justified to the extent that the oedema event is predictable from the ingestion of shellfish, according to the classical approach of the 'received view' in philosophy of science. Yet, if we only rely on the statistical probability of the glottal oedema given the ingestion of shellfish, the absence of an oedema, rather than its appearance, is also predictable. Additionally, the absence of an oedema would have been predictable with even higher probability, if one were able to verify with certainty that James did not come into contact with any other (known or unknown) allergen. Perhaps the knowledge of certain physiological features of James would have allowed the clinician to make a reliable prediction of the appearance of the glottal oedema, but such knowledge was not, and is not available.

We assume that the relation of causation cannot be eliminated, or reduced to other notions, and we will consider how it is possible to assign a probabilistic value to the causal statement $(\mathrm{C})$. Note that the clinician already knows that James has a glottal oedema. His/her final objective is not to ascertain the degree of probability for James to develop the oedema after the ingestion of shellfish, but rather to treat the oedema; in this sense it may be useful for the clinician to know what has caused the oedema in order to remove it. The etiological knowledge may also be useful for preventing future oedemas and this could be an additional motivation for the search of the cause.

Since the clinician cannot fully ascertain the cause with complete certainty, he/ she can try to ascertain what the probabilities of the single possible alternative 
known causes are; that is, for each possible cause, the clinician can assess the conditional probability of the oedema given the cause and the other relevant information. Based on such probabilities, the clinician can easily see which one holds the highest rank.

In this research, the clinician is faced with two problems. In the first place, the conditional statistical probability of a possible cause, given the morbid phenomenon, is not often immediately available. Secondly, the clinician must take into account what he/she knows about James. Regarding the first issue, the inverse probabilities of the morbid phenomenon given the possible cause and the initial epidemiologically based probabilities can be more readily known. Suppose that these probabilities are known, and therefore the requested conditional probabilities may be indirectly reconstructed from them. In order to consider the special features of James - this is the other problem to deal with - the clinician could transform these probabilities into subjective-epistemic probabilities. By benefitting from a basic idea by Salmon and applying Bayesianism, the clinician may proceed as follows.

We refer to as large as possible a population $\mathrm{R}$ of individuals who came into contact with at least one known allergen, and we call A the property of having a glottal oedema. For each set of known allergens, consider the property of having come into contact with the allergens of the set. For the sake of simplicity, we assume that there are only two allergens, $c_{1}$ and $c_{2}$, corresponding to the $\mathrm{C}_{1}$ property of having been in contact with $\mathrm{c}_{1}$ and the $\mathrm{C}_{2}$ property of having been in contact with $c_{2}$. The properties to be considered are therefore $C_{1} \wedge \neg C_{2}$, $\mathrm{C}_{2} \wedge \neg \mathrm{C}_{1}$ and $\mathrm{C}_{1} \wedge \mathrm{C}_{2}$. Call, respectively, $\mathrm{K}_{1}, \mathrm{~K}_{2}$ and $\mathrm{K}_{3}$, their restrictions to $\mathrm{R}^{8}$ and suppose that the statistical probabilities $\mathrm{P}(\mathrm{A} / \mathrm{R})$ and $\mathrm{P}\left(\mathrm{A} / \mathrm{K}_{\mathrm{i}}\right), 1 \leq \mathrm{i} \leq 3$, are known. Suppose also that $\mathrm{P}\left(\mathrm{A} / \mathrm{K}_{\mathrm{i}}\right) \neq \mathrm{P}(\mathrm{A} / \mathrm{R})$ for all $\mathrm{i}$. It follows that every property $\mathrm{K}_{\mathrm{i}}$ is statistically relevant for A within $\mathrm{R}$, following Salmon's definition of this notion. According to the way in which $\mathrm{K}_{\mathrm{i}}$ has been introduced, and based on the shared scientific knowledge, $\mathrm{K}_{\mathrm{i}}$ (with $\mathrm{i} \leq 3$ ) can have causal efficacy for A; namely, having the property $\mathrm{K}_{\mathrm{i}}$ may causally determine having the property $A$, since $c_{1}$ or $c_{2}$ can cause the oedema of the glottis. Even if $\mathrm{K}_{3}$ is defined by the exposure $\mathrm{C}_{1} \wedge \mathrm{C}_{2}$, the causal role of $\mathrm{K}_{3}$ may be due to the causal efficacy of only $\mathrm{c}_{1}$, of only $c_{2}$ or of both $c_{1}$ and $c_{2}$. Assume that for the cases of oedema in $\mathrm{K}_{3}$ there is no possibility of identifying which of these possibilities took place.

A, $K_{1}, K_{2}$ and $K_{3}$ isolate certain classes to which we refer in the same manner. 
Let us wonder whether, based on the already acquired knowledge- that is, the scientific knowledge $s$ and evidence $e$-, we know some conditions $\mathrm{F}$ contributing to the causation of the glottal oedema, such that $\mathrm{P}\left(\mathrm{A} / \mathrm{K}_{\mathrm{i}} \wedge \mathrm{F}\right)>\mathrm{P}\left(\mathrm{A} / \mathrm{K}_{\mathrm{i}}\right)$. If the answer is negative, we say that the class described by $\mathrm{K}_{\mathrm{i}}$ is epistemically and causally homogeneous with respect to $\mathrm{A}, s$ and $e$. If, for each $\mathrm{i}$, the class described by $\mathrm{K}_{\mathrm{i}}$ is epistemically and causally homogeneous with respect to $\mathrm{A}, s$ and $e$, the partition $\mathrm{K}$ of $\mathrm{R}$ in $\mathrm{K}_{1}, \mathrm{~K}_{2}$ and $\mathrm{K}_{3}$ is epistemically and causally homogeneous with respect to $\mathrm{A}, s$ and $e$.

The main distinction between the notion of homogeneity and that of Salmon regards the restriction of the quantification to the conditions that have a causal role for the explanandum. Of course, speaking of a causal role introduces some lack of clarity that the context may eliminate partially, but not completely. On the other hand, there now seems to be a broad consensus that it is not possible to provide an eliminative reduction of the relation of causation. In addition, because of the irreflexivity of the causation relation, speaking of a condition $\mathrm{F}$ endowed with causal role for the explanandum $\mathrm{A}$ is advantageous for immediately excluding that $\mathrm{A}$ itself may be regarded as one of the conditions $\mathrm{F}$ by which to assess the homogeneity of the classes of the considered partition.

Is the concept of epistemic causal homogeneity useful to the clinician dealing with James' case? $\mathrm{K}_{\mathrm{i}}$ is epistemically and causally homogeneous with respect to $\mathrm{A}$, if any further causal specification of $\mathrm{K}_{\mathrm{i}}$ is not known such as to make A more likely. The idea that we want to capture is that having the property $\mathrm{K}_{\mathrm{i}}$ is known as causally contributing to having $\mathrm{A}$, and there is nothing more that one can know about it.

If James has the property $\mathrm{K}_{\mathrm{i}}$, if $\mathrm{K}_{\mathrm{i}}$ is epistemically and causally homogeneous with respect to $\mathrm{A}$, and if that is known as a part of the total available evidence, it is reasonable to require that the clinician assigns to James a probability of developing a glottal oedema that depends on the statistical probability $\mathrm{P}\left(\mathrm{A} / \mathrm{K}_{\mathrm{i}}\right)$. More precisely, if James is called $\mathrm{j}$, it is natural to require and to assume that the subjective probability $p$ of the clinician and the evidence $e$ available to him/her are such that:

$$
p(\mathrm{Aj} / e)=p\left(\mathrm{Aj} /\left(\mathrm{K}_{\mathrm{j}} \mathrm{j} \wedge \mathrm{P}\left(\mathrm{A} / \mathrm{K}_{\mathrm{i}}\right)=\mathrm{q}\right)\right)
$$

that is, the subjective probability that the clinician assigns to $\mathrm{Aj}$ given $e$ is determined by the subjective probability of $A j$ given both $K_{j} j$ and $P\left(A / K_{i}\right)=q$, 
where $\mathrm{P}\left(\mathrm{A} / \mathrm{K}_{\mathrm{i}}\right)$ is the statistical probability of $\mathrm{A}$ in $\mathrm{K}_{\mathrm{i}}{ }^{9}$ If it is certain that $\mathrm{P}(\mathrm{A} /$ $\left.\mathrm{K}_{\mathrm{i}}\right)=\mathrm{q}$, then $p\left(\mathrm{Aj}_{\mathrm{j}}\left(\mathrm{K}_{\mathrm{i}} \wedge \mathrm{P}\left(\mathrm{A} / \mathrm{K}_{\mathrm{i}}\right)=\mathrm{q}\right)\right)=p\left(\mathrm{Aj}_{\mathrm{j}} / \mathrm{K}_{\mathrm{i}}\right)$. Moreover, we assume that no other relevant information is available, so that it is also natural to assume:

$$
p\left(\mathrm{Aj} / \mathrm{K}_{\mathrm{j}}\right)=\mathrm{q}
$$

that is, the subjective probability of $A j$ given $K_{j} j$ has the same value $q$ as the statistical probability $\mathrm{P}\left(\mathrm{A} / \mathrm{K}_{\mathrm{i}}\right){ }^{10}$

If we already know that James had a glottal oedema and that he belongs moreover to a specific $\mathrm{K}_{\mathrm{i}}$, then the knowledge of the causal role of $\mathrm{K}_{\mathrm{i}}$ justifies a corresponding attribution of causality, even when $\mathrm{P}\left(\mathrm{A} / \mathrm{K}_{\mathrm{i}}\right)$ is low. ${ }^{11}$ In this case, the value of the statistical probability $\mathrm{P}\left(\mathrm{A} / \mathrm{K}_{\mathrm{i}}\right)$ does not have any significant role, as it falls within the deductive reconstruction of the argument.

However, we are now considering the case in which the clinician does not accept $\left(\mathrm{B}_{3}\right)$ and therefore does not know that James belongs to a specific subclass $\mathrm{K}_{\mathrm{i}}$. For each subclass $\mathrm{K}_{\mathrm{i}}$, the clinician may have uncertain evidence of James' belonging to $\mathrm{K}_{\mathrm{i}}$. Suppose, for example, that his/her subjective evaluations are the following:

$$
\begin{aligned}
& p\left(\mathrm{~K}_{1} \mathrm{j}\right)=0.4 \\
& p\left(\mathrm{~K}_{2} \mathrm{j}\right)=0.5 \\
& p\left(\mathrm{~K}_{3} \mathrm{j}\right)=0.1
\end{aligned}
$$

In general, the subjective evaluations of the clinician can vary within a very wide range, but they should be compatible with a correct use of the available information. Notably, the clinician should not assess James' belonging to a specific $\mathrm{K}_{\mathrm{i}}$ as being more likely, only because (using the example) the oedema of the glottis would be statistically more likely in $\mathrm{K}_{\mathrm{i}}$. The incorrectness of such an assessment should be intuitively evident if we consider the case of a $\mathrm{K}_{\mathrm{i}}$ with very few elements. The possible higher level of probability of $A$ in $K_{i}$ can surely not be a reason for considering James' belonging to $\mathrm{K}_{\mathrm{i}}$ as more likely.

9 We are assuming the possibility of a fully subjective interpretation of probability, including conditional probability and a posteriori probability.

10 See (Festa, 2004, p. 60 and p. 64). We emphasize the assumption that the statistical probabilities have been correctly determined and are certain.

11 More precisely, James' assignment to $\mathrm{K}_{1}$ justifies the identification of the cause of his oedema with $\mathrm{c}_{1}$, James' assignment to $\mathrm{K}_{2}$ justifies the identification of the cause of his oedema with $\mathrm{c}_{2}$, James' assignment to $\mathrm{K}_{3}$ leaves open any causal attribution. 
Concerning the conditional probabilities of the type $p\left(\mathrm{Aj}_{\mathrm{j}} / \mathrm{K}_{\mathrm{j}} \mathrm{j}\right)$, let us continue to assume that the total evidence available to the clinician is not such as to make $p\left(\mathrm{Aj}_{\mathrm{j}} / \mathrm{K}_{\mathrm{i}}\right)$ different from $\mathrm{P}\left(\mathrm{A} / \mathrm{K}_{\mathrm{i}}\right)$. For purely illustrative purposes, we can suppose that the clinician endorses the following, completely hypothetical, conditional probabilities:

$$
\begin{aligned}
& p\left(\mathrm{Aj}_{\mathrm{j}} / \mathrm{K}_{1} \mathrm{j}\right)=0.2 \\
& p\left(\mathrm{Aj} / \mathrm{K}_{2} \mathrm{j}\right)=0.1 \\
& p\left(\mathrm{Aj}_{\mathrm{j}} / \mathrm{K}_{3} \mathrm{j}\right)=0.3
\end{aligned}
$$

From Bayes' theorem, it follows that:

$$
\begin{aligned}
p\left(\mathrm{~K}_{1} \mathrm{j} / \mathrm{Aj}\right)= & (0.4 \times 0.2) /(0.4 \times 0.2+0.5 \times 0.1+0.1 \times 0.3)= \\
& 0.08 /(0.08+0.05+0.03)=0.08 / 0.16=0.5 \\
p\left(\mathrm{~K}_{2} / \mathrm{Aj}\right)= & (0.5 \times 0.1) / 0.16=0.05 / 0.16=0.31 \\
p\left(\mathrm{~K}_{\mathrm{j}} / \mathrm{Aj}\right)= & (0.1 \times 0.3) / 0.16=0.03 / 0.16=0.18
\end{aligned}
$$

Thus, the probability of belonging to the class $\mathrm{K}_{1}$ given the glottal oedema is greater than the other conditional probabilities of the same type. Since there is a causal significance of $\mathrm{K}_{1}$ with respect to $\mathrm{A}$, it seems reasonable to conclude that the probability that $\mathrm{C}_{1}$ caused James' oedema is the highest because the probability of James' belonging to $\mathrm{K}_{1}$ (given his oedema) is the highest.

\section{The clinical case: third version}

Suppose now that the initial uncertainty is even greater. The clinician does not accept $\left(\mathrm{B}_{3}\right)$ (after the ingestion of shellfish and before the onset of the oedema of the glottis, James did not come into contact with known allergens other than those contained in shellfish, and previous contact with a known allergen could not have caused the oedema). The clinician does not even accept $\left(\mathrm{C}_{2}\right)$ (James did not come into contact with any unknown allergens), as he/she is not willing to exclude any unknown-allergen contact for James. Obviously, the deduction of (C) is not possible and, again, it is no longer possible to assess the probability of (C) based on the way in which the uncertainty of the premises is transmitted to the conclusion through deductions. 
The (partial) statistical-causal analysis proposed above cannot be reapplied without incurring major changes.

In this case too, we assume that the known allergens are only $c_{1}$ and $c_{2}$, corresponding to the property $\mathrm{C}_{1}$ of having been in contact with $\mathrm{c}_{1}$ and to the property $\mathrm{C}_{2}$ of having been in contact with $\mathrm{c}_{2}$. The reference class is a population $\mathrm{R}$, which this time includes individuals who have not come into contact with any known allergen. Thus, four properties need to be considered: $C_{1} \wedge \neg C_{2}, C_{2} \wedge \neg C_{1}$, $\mathrm{C}_{1} \wedge \mathrm{C}_{2}$ and $\neg \mathrm{C}_{1} \wedge \neg \mathrm{C}_{2}$. For each of their restrictions to $\mathrm{R}$ - call them, respectively, $\mathrm{K}_{1}, \mathrm{~K}_{2}, \mathrm{~K}_{3}$ and $\mathrm{K}_{4}$ - let us suppose that we know the statistical probability $\mathrm{P}(\mathrm{A} /$ $\left.K_{i}\right), 1 \leq \mathrm{i} \leq 4$, given by the frequency of $A$ in $K_{i}$. If $P\left(A / K_{i}\right) \neq P(A / R)$, the property $\mathrm{K}_{\mathrm{i}}$ is statistically relevant for A within $\mathrm{R}$.

Assume that for each $\mathrm{i} \leq 3 \mathrm{P}\left(\mathrm{A} / \mathrm{K}_{\mathrm{i}}\right)>\mathrm{P}(\mathrm{A} / \mathrm{R})$, but $\mathrm{P}\left(\mathrm{A} / \mathrm{K}_{4}\right)<\mathrm{P}(\mathrm{A} / \mathrm{R}) . \mathrm{K}_{1}, \mathrm{~K}_{2}$ and $\mathrm{K}_{3}$ may have causal efficacy for $\mathrm{A}$ in the same sense that is assumed above. However, it is difficult to argue that $\mathrm{K}_{4}$, namely, $\neg \mathrm{C}_{1} \wedge \neg \mathrm{C}_{2}$, has causal efficacy for A. The clinician is convinced that A may also have causes other than $\mathrm{c}_{1}$ or $\mathrm{c}_{2}$, but he/she is oblivious to how many or what they may be. In addition, since $\mathrm{P}\left(\mathrm{A} / \mathrm{K}_{4}\right)<\mathrm{P}(\mathrm{A} / \mathrm{R}), \mathrm{K}_{4}$ does not make A more likely.

Suppose, for each $\mathrm{i} \leq 4$, and therefore also for $\mathrm{i}=4$, that no conditions $\mathrm{F}$ are known, which are endowed with causal efficacy for $A$ and are such that $\mathrm{P}(\mathrm{A} /$ $\left.\mathrm{K}_{\mathrm{i}} \wedge \mathrm{F}\right)>\mathrm{P}\left(\mathrm{A} / \mathrm{K}_{\mathrm{i}}\right)$. Still, since it is not possible to provide any reason for the causal role of $\mathrm{K}_{4}, \mathrm{~K}_{4}$ cannot be regarded as epistemically and causally homogeneous with respect to $\mathrm{A}$ and to the available knowledge. Then, it is not even possible to consider the partition $\mathrm{K}$ of $\mathrm{R}$ in $\mathrm{K}_{1}, \mathrm{~K}_{2}, \mathrm{~K}_{3}$ and $\mathrm{K}_{4}$ as epistemically and causally homogeneous with respect to $\mathrm{A}$ and to the available knowledge.

It may, therefore, not be possible to assign a higher probability to a specific causal attribution. This takes place when James comes out as most likely belonging to the class $\mathrm{K}_{4}$. Suppose, for example:

$$
\begin{array}{ll}
p\left(\mathrm{~K}_{1} \mathrm{j}\right)=0.1 & p\left(\mathrm{Aj}_{\mathrm{j}} / \mathrm{K}_{\mathrm{j}} \mathrm{j}\right)=0.4 \\
p\left(\mathrm{~K}_{2} \mathrm{j}\right)=0.2 & p\left(\mathrm{Aj}_{\mathrm{j}} \mathrm{K} \mathrm{j}\right)=0.5 \\
p\left(\mathrm{~K}_{3} \mathrm{j}\right)=0.1 & p\left(\mathrm{Aj}_{\mathrm{j}} \mathrm{\textrm {K } _ { 3 }}\right)=0.6 \\
p\left(\mathrm{~K}_{4} \mathrm{j}\right)=0.6 & p\left(\mathrm{Aj}_{\mathrm{j}} / \mathrm{K}_{4} \mathrm{j}\right)=0.2
\end{array}
$$


It follows that:

$$
\begin{aligned}
p\left(\mathrm{~K}_{1} \mathrm{j} / \mathrm{Aj}\right)= & (0.1 \times 0.4) /(0.1 \times 0.4+0.2 \times 0.5+0.1 \times 0.6+0.6 \times 0.2)= \\
& 0.04 /(0.04+0.1+0.06+0.12)=0.04 / 0.32=0.12 \\
p\left(\mathrm{~K}_{2} \mathrm{j} / \mathrm{Aj}\right)= & (0.2 \times 0.5) / 0.32=0.1 / 0.32=0.31 \\
p\left(\mathrm{~K}_{3} \mathrm{j} / \mathrm{Aj}\right)= & (0.1 \times 0.6) / 0.32=0.06 / 0.32=0.18 \\
p\left(\mathrm{~K}_{4} \mathrm{j} / \mathrm{Aj}\right)= & (0.6 \times 0.2) / 0.32=0.12 / 0.32=0.37
\end{aligned}
$$

In this case, James' probability of not having come into contact with any of the known allergens is the highest. Note, moreover, that upon admission of the existence of an unknown allergen, even the certainty of contact with the known allergen does not rule out other possible contact with an unknown allergen, and that the latter may have caused the oedema.

\section{The clinical case: fourth version}

How should one proceed when one observes a glottal oedema in the caseentirely fictional — in which no possible cause is known? Suppose that the clinician knows only that certain conditions favour the appearance of the oedema; namely, that the oedema is more frequent among those who satisfy at least one of certain conditions. In epidemiological terms, we can say that we only know of some risk factors for the oedema of the glottis. In general, risk factors cannot be considered as causes and their knowledge might have no utility in terms of diagnosis and treatment. Suppose, however, that certain conditions are useful in determining the type of oedema, the prognosis and possibly the treatment. In this case, it is natural to try to determine what the condition was that favoured James' oedema, as it would be useful information from the clinical point of view, even if it was not sufficient to identify a cause with certainty and precision.

But what type of conditions are we to consider? The clinician should draw information from his/her pathological and epidemiological knowledge, but he/ she should also be guided by some methodological principles that are justified by general epistemological considerations. In particular, although in the case imagined it is not possible to speak of causes, but only of favourable conditions, it is natural to rule out those conditions that do not satisfy some formal properties 
of the causes, even if the conditions not excluded cannot be qualified as causes. In particular, $\mathrm{D}$ can be a cause of $\mathrm{E}$ neither if it takes place after $\mathrm{E}$, nor if both $\mathrm{D}$ and $\mathrm{E}$ are direct effects of a third event $\mathrm{C}$ (a conjunctive fork).

In the following, we will only touch upon some basic ideas proposed by Hans Reichenbach and Patrick Suppes, with the understanding that the line of research they set forth does not necessarily lead to a satisfactory notion of probabilistic causality. Reichenbach's and Suppes' proposals mainly concern the problem of distinguishing between correlations and causality, as well as the problem of recovering an asymmetrical probabilistic causal relation so as to have the probabilistic cause preceding the probabilistic effect.

The first problem concerns the conjunctive fork, which is defined by Reichenbach as follows:

1. $0<\mathrm{P}(\mathrm{C})<1$

2. $\quad \mathrm{P}(\mathrm{D} \wedge \mathrm{E} / \mathrm{C})=\mathrm{P}(\mathrm{D} / \mathrm{C}) \mathrm{P}(\mathrm{E} / \mathrm{C})$

3. $\quad \mathrm{P}(\mathrm{D} \wedge \mathrm{E} / \neg \mathrm{C})=\mathrm{P}(\mathrm{D} / \neg \mathrm{C}) \mathrm{P}(\mathrm{E} / \neg \mathrm{C})$

4. $\quad \mathrm{P}(\mathrm{D} / \mathrm{C})>\mathrm{P}(\mathrm{D} / \neg \mathrm{C})$

5. $\quad \mathrm{P}(\mathrm{E} / \mathrm{C})>\mathrm{P}(\mathrm{E} / \neg \mathrm{C})$

Condition 1 states that the probability of the event $\mathrm{C}$ is in the open interval $(0,1)$, conditions 2 and 3 state that $\mathrm{D}$ and $\mathrm{E}$ are probabilistically independent with respect to $C$ and to $\neg C$, while conditions 4 and 5 state that $C$ is positively relevant for both $\mathrm{D}$ and $\mathrm{E}$. It is often said that $\mathrm{C}$ and $\neg \mathrm{C}$ screen off $\mathrm{D}$ from $\mathrm{E}$. Conditions $1-5$ entail 6:

6. $\mathrm{P}(\mathrm{D} \wedge \mathrm{E})>\mathrm{P}(\mathrm{D}) \mathrm{P}(\mathrm{E})$; namely, there is a positive correlation between $\mathrm{D}$ and $\mathrm{E}$, but this is due to the common 'cause' C.

Thus, if there is a positive correlation between $\mathrm{D}$ and $\mathrm{E}$ and there is an event $\mathrm{C}$ which satisfies $1-5$, then $\mathrm{C}$ is a (probabilistic) cause for both $\mathrm{D}$ and $\mathrm{E}$, and this fact explains the lack of independency between D and E (Reichenbach, 1956). ${ }^{12}$

Regarding the second problem, Suppes assumes, as a primitive fact, that a cause temporally precedes its effects. On the basis of that, he introduces the idea of a

12 It has been observed that when more events screen off $\mathrm{D}$ from $\mathrm{E}$, the notion of the conjunctive fork is not sufficient to individuate a common cause (Uffink, 1999), but we will not go into this issue herein. 
prima facie 'cause' such that when it occurs, it increases the probability of the effects (Suppes, 1970). Suppes states that $C$ at $t$ ', shortly $C_{t}$, is a prima facie 'cause' of $\mathrm{E}$ at $\mathrm{t}$, shortly $\mathrm{E}_{\mathrm{t}}$, if and only if:

$$
\begin{aligned}
& \mathrm{t}^{\prime}<\mathrm{t} \\
& \mathrm{P}\left(\mathrm{C}_{\mathrm{t}}\right)>0
\end{aligned}
$$

$\mathrm{P}\left(\mathrm{E}_{\mathrm{t}} / \mathrm{C}_{\mathrm{t}}\right)>\mathrm{P}\left(\mathrm{E}_{\mathrm{t}}\right)$, which holds only in cases where $\mathrm{P}\left(\mathrm{E}_{\mathrm{t}} / \mathrm{C}_{\mathrm{t}}\right)>\left(\mathrm{E}_{\mathrm{t}} / \neg \mathrm{C}_{\mathrm{t}}\right)$ holds.

He later defines a strong notion of a spurious cause as follows: $C_{i}$ is a spurious 'cause' of the event $\mathrm{E}_{\mathrm{t}}$ if and only if $\mathrm{C}_{\mathrm{t}}$ is a prima facie 'cause' of $\mathrm{E}_{\mathrm{t}}$ and there is a partition $\left\{\mathrm{K}_{1, \mathrm{t},}, \mathrm{K}_{2, \mathrm{t}^{\prime \prime}}, \ldots, \mathrm{K}_{\mathrm{n}, \mathrm{t}}\right\}$ such that

$$
\begin{aligned}
& \mathrm{t}^{\prime \prime}<\mathrm{t}^{\prime} \\
& \mathrm{P}\left(\mathrm{E}_{\mathrm{t}} / \mathrm{C}_{\mathrm{i}} \wedge \mathrm{K}_{\mathrm{i}, \mathrm{t}^{\prime \prime}}\right)=\mathrm{P}\left(\mathrm{E}_{\mathrm{t}} / \mathrm{K}_{\mathrm{i}, \mathrm{t}^{\prime}}\right) \text {, where } \mathrm{i} \text { is a natural number belonging to }[1, \mathrm{n}] .
\end{aligned}
$$

A genuine cause is a non-spurious prima facie 'cause'.

The search for a satisfactory notion of probabilistic causality ${ }^{13}$ continued and attempts were made to face the many paradoxes that were more or less associated with it (the Simpson Paradox, the Lindrey-Jeffrey Paradox, etc.). In the following, we merely hint at a simple way in which the basic idea of screening off-which was already tacitly applied — might be slightly modified by adding a temporal reference and is then used for diagnostic purposes in the new imaginary version of our case, where no proper causal knowledge is assumed to be available.

The reference class is made up of a population $\mathrm{R}$, which we assume to be divided on the basis of the conditions $C_{1}$ and $C_{2}$ in such a way that the properties $C_{1} \wedge \neg C_{2}$, $\mathrm{C}_{2} \wedge \neg \mathrm{C}_{1}, \mathrm{C}_{1} \wedge \mathrm{C}_{2}$ and $\neg \mathrm{C}_{1} \wedge \neg \mathrm{C}_{2}$ determine a partition $\mathrm{K}$ in the corresponding classes $\mathrm{K}_{1}, \mathrm{~K}_{2}, \mathrm{~K}_{3}$ and $\mathrm{K}_{4}$. Let $\mathrm{K}_{\mathrm{i}, \mathrm{t}}$ be the class of the instances of $\mathrm{K}_{\mathrm{i}}$ at $\mathrm{t}$ and $\mathrm{A}_{\mathrm{t}}$ the class of instances of $A$ at $t^{\prime}$, where $t<t^{\prime}$. We can request that $K_{i, t}$ should be considered as a condition that favours $\mathrm{A}_{t^{\prime}}$ only if ${ }^{14}$ there is no known condition $\mathrm{C}_{\mathrm{t}^{*}}$, defined on $\mathrm{R}$, where $\mathrm{t}^{*}<\mathrm{t}$, such that $\mathrm{C}_{\mathrm{t}^{*}}$ screens off $\mathrm{K}_{\mathrm{i}, \mathrm{t}}$ from $\mathrm{A}_{\mathrm{t}^{*}}$. Then, the diagnostic process may proceed as above, transforming statistical probabilities of the form $\mathrm{P}(/)$ into a subjective-epistemic probability of the form $p(/)$ with the aim of seeking for which $\mathrm{K}_{\mathrm{i}, \mathrm{t}} p\left(\mathrm{~K}_{\mathrm{i}, \mathrm{j}} \mathrm{j} / \mathrm{A}_{\mathrm{t}} \mathrm{j}\right)$ is the highest.

\footnotetext{
13 The original motivation for this line of research was a reductionist one. See Salmon (1980) for a critique of such motivation, which is now generally abandoned.

14 What follows 'only if' is proposed as a necessary condition that is open to further specification.
} 
Note that also other requirements, formulated to reach a satisfactory concept of probabilistic causality, can or should help lead the search towards an informative condition about the pathology affecting a patient (when its origin and evolution are widely unknown).

\section{The final, though not minor, problem}

The classes into which the reference population has been partitioned correspond to the number of hypotheses about the cause or condition that have favoured James' oedema. The assignment of James into any of these classes has an initial plausibility that the clinician can quantify by means of probabilistic values representing the extent of his/her initial confidence in their truth. As emphasized above, these values should be used as the basis by which to calculate the probability of James' belonging to each class, given the oedema.

As stated by Johansson and Lynøe (2008, p. 134), "it is difficult, not to say impossible, to ascribe numerical values to epistemic statements". However, there are procedures that may help the clinician explicitly and soundly to assess the epistemic initial probabilities.

Note that it is also possible that the clinician's assessment of the initial probability ends up being inconsistent. The so-called expert elicitation can be applied to single out and eliminate potential inconsistencies. Many techniques of eliciting probabilities are available (Slottje, Sluijs \& Knol, 2008). According to one of these techniques, the expert is asked to evaluate whether the actual value of a quantity is higher or lower than a certain number. This can be carried out, for instance, by means of graphical tools such as probabilistic wheels. Alternatively, the expert is asked to fix the value of a quantity such that the probability of higher or lower values turns out to be some specific amount. We do not go into the analysis of these techniques. What is important for our discussion is that the clinician should be aware of the possibility of incurring inconsistencies and also of the availability of some methods for avoiding these. ${ }^{15}$

Moreover, even if clinician's assessments of the probabilities relevant to a specific clinical problem comply with the rules of the probability calculus, nonetheless

15 However, we do not rule out the possibility that the clinician may face some kinds of fundamental uncertainty in which probabilities are not well definable or computable and some forms of abductive reasoning are required (Chiffi \& Pietarinen, 2017). 
they might turn out to be arbitrary, at least to a certain extent. Arbitrariness should be limited and, in fact, can be reduced by taking into account the epidemiological information. Of course, epidemiological data is not always relevant when dealing with a clinical case. It seems reasonable to hold that it may be relevant for the analysis of a clinical case when some of the following conditions are fulfilled (Lagiou, Adami \& Trichopoulos, 2005):

1. The exposure to risk factors is also an established cause of the disease;

2. The exposure of the individual is similar (as regarding duration, intensity, latency) to the exposure causing the disease;

3. The disease of the individual must be similar to that which is etiologically associated with the exposure;

4. The individual has to be not exposed to other risk factors; and

5. The relative risk (RR) - namely, the ratio of the probability of the disease in the exposed population to that in the unexposed population-must be greater than 2. If the $\mathrm{RR}$ is lower than 2, then the association between the exposure to the risk factor and the disease needs to be carefully analysed and methodologically motivated, since a weak association does not rule out the possibility of the clinical relevance of such an association.

These conditions must not be seen as robust criteria supporting the use of epidemiological data in the clinical context, but rather as constraints functioning as standards that guide the integration of epidemological evidence in clinical practice. It is important to stress that the clinician's decision-making process can greatly benefit from clinical guidelines. Of course, the clinician can break away from the guidelines if there is a reasonable motivation for a different judgment. Nevertheless, such subjective judgment, even when it is formally consistent, cannot be arbitrary but should be methodologically constrained and explicitly justifiable based on the theoretical and empirical knowledge available given the specific situation. 


\section{Concluding remarks}

We discussed the role of causality and probability assignments in relation to a clinical case that seemed to us to be quite significant. The analysis that has been carried out is grounded on some theses about the nature of the physician's diagnostic activity. Initially, we endorsed the idea that clinical diagnosis is based on pathological knowledge that has already been acquired and that it is not intended to extend this knowledge, although it might unintentionally lead to the acquisition of information that is useful for its extension. Secondly, we observed that presupposed knowledge can be both causal knowledge and correlation knowledge. Causal knowledge concerns events that trigger disease processes and the very mechanisms by which these processes evolve. Based on classical and recent research concerning the notion of cause, we hold that this concept is not completely reducible to other concepts, and that a primitive idea of causal relationship may tacitly underlie the research of correlations that are relevant for medical knowledge.

We emphasized that the role of probability is crucial. It is even crucial to assess the confidence to be accorded to conclusions obtained deductively from not entirely certain premises. In our view, we are bound to assume that the clinician's assignment of probability to a specific case is the result of his/her own evaluation, leading us to conclude that probabilities are to be regarded as subjective. However, it is quite natural to request non-arbitrary and (as far as possible) statisticallybased probabilities.

It seems to us that in clinical diagnosis initial probabilities are more difficult to connect with statistical data. That is not surprising and, to a certain extent, is as it should be. There is, however, a problem in assuring the consistency and limiting the arbitrariness of the clinician's evaluations. We hinted at some indications, taken from the literature, which might be useful for this purpose. Some conditional probabilities are rather more easily identifiable with suitable statistical frequencies. The identification requires a high degree of normative idealization and we derived from the literature some indications about the ideal way in which this identification can be pursued. In a less idealized approach, there might be other more general, justified ways in which the clinician may transform the conditional statistical probabilities into subjective conditional probabilities regarding the patient he/she is taking care of.

After all, it appears that two kinds of probability have a definite role: the frequency-objective and the epistemic/subjective. Is there any role for some 
other kind of probability, in particular, for a notion of probability as propensity? Surely, the clinician may base his probabilistic assessment of a patient having a certain disease on a more or less justified attribution of certain propensities to $\mathrm{him} / \mathrm{her}$. But is this enough, or are other reasons also needed to identify a role for a specific kind of a propensity-based singular-objective probability? We do not exclude that a deep understanding of medicine in general, not only of clinical activity, might require some room for a propensity interpretation of probability. However, a further separate and dedicated analysis is needed. ${ }^{16}$

\section{Acknowledgements}

The research of Daniele Chiffi has been supported by the Estonian Research Council ('Abduction in the Age of Fundamental Uncertainty', PUT 1305, PI: A.-V. Pietarinen) and by the Portuguese Foundation for Science and Technology (PTDC/MHC-FIL/0521/2014; PI: Erich Rast). The research of Pierdaniele Giaretta has been supported with the funds of the project 'Tracing the History of Words. A Portrait of a Discipline Through Analyses of Keyword Counts in Large Corpora of Scientific Literature', directed by Arjuna Tuzzi (CPDA145940, University of Padua). We thank Ingvar Johansson for his remarks on an earlier version of this paper and the two anonymous referees.

\section{References}

Adams, E. W. (1965), 'The Logic of Conditionals,' Inquiry, vol. 8, pp. 166-197. https://doi.org/10.1080/00201746508601430

Adams, E. W. (1975), The Logic of Conditionals: An Application of Probability to Deductive Logic, Dordrecht: D. Reidel. https://doi.org/10.1007/978-94-015-7622-2

Adams, E. W. (1998), A Primer of Probability Logic, Stanford: CSLI Publications.

Antiseri, D. (1981), Teoria unificata del metodo, Padova: Liviana.

Biernacki, E. ([1899] 1991), 'The Essence and the Limits of Medical Knowledge,' in I. Löwy (ed.) The Polish School of Philosophy of Medicine. From Tytus Chalubinski (1820-1889) to Ludwik Fleck (1896-1961), Dordrecht: Kluwer Academic Publishers, pp. 50-57.

16 The present paper is a substantially modified, corrected, and extended version of the following lacunose scientific contribution: Giaretta \& Chiff, 2013. 
Chiff, D. \& Pietarinen, A.-V. (2017), 'Fundamental uncertainty and values,' Philosophia, vol. 45, no. 3, pp. 1027-1037. https://doi.org/10.1007/s11406-017-9865-5

Federspil, G. (2004), Logica clinica. I principi del metodo in medicina, Milano: McGraw Hill.

Federspil, G. (2005), 'Spiegazione e causalità in medicina,' Nuova Civiltà delle Macchine, vol. 23 , pp. 67-86.

Federspil, G. (2010), 'Diagnosi,' in A. Pagnini (ed.) Filosofia della medicina. Epistemologia, ontologia, etica, diritto, Roma: Carocci, pp. 277-290.

Festa, R. (2004), 'Principio di evidenza totale, decisioni cliniche ed Evidence Based Medicine,' in G. Federspil \& P. Giaretta (eds.) Forme della razionalià medica, Soveria Mannelli: Rubbettino, pp. 47-82.

Giaretta, P. \& Chiffi, D. (2013), 'Causal attribution and crossing over between probabilities in clinical diagnosis,' in C. Svennerlind, J. Almäng \& R. Ingthorsson (eds.) Johanssonian Investigations. Essays in Honour of Ingvar Johansson on His Seventieth Birthday, Frankfurt: Ontos Verlag, pp. 191-211. https://doi.org/10.1515/9783110322507.191

Hájek, A. (2001), 'Probability, logic, and probability logic,' in L. Goble (ed.) The Blackwell Companion to Logic, Oxford: Blackwell, pp. 362-384.

Johansson, I. \& Lynøe, N. (2008), Medicine \& Philosophy. A Twenty-First Century Introduction, Frankfurt: Ontos Verlag. https://doi.org/10.1515/9783110321364

Lagiou, P.; Adami, H., \& Trichopoulos, D. (2005), 'Causality in cancer epidemiology,' European Journal of Epidemiology, vol. 20, pp. 565-574.

https://doi.org/10.1007/s10654-005-7968-y

Löwy, I., ed. (1991), The Polish School of Philosophy of Medicine. From Tytus Chalubinski (1820-1889) to Ludwik Fleck (1896-1961), Dordrecht: Kluwer Academic Publishers.

MeSH (Medical Subject Headings) (2018), 'Laryngeal Edema,' The National Library of Medicine. Retrieved from https://www.ncbi.nlm.nih.gov/mesh/68007819 [accessed 12 Mar 2018]

Murri, A. (1972), Quattro lezioni e una perizia. Il problema del metodo in medicina e biologia, Bologna: Zanichelli.

Murri, A. (2004), Dizionario di metodologia clinica, ed. by M. Baldini \& A. Malavasi, Roma: A. Delfino Editore.

Reichenbach, H. (1956), The Direction of Time, Berkeley \& Los Angeles: University of California Press.

Salmon, W. C. (1980), 'Probabilistic causality', Pacific Philosophical Quarterly, vol. 61, pp. 50-74. https://doi.org/10.1111/j.1468-0114.1980.tb00004.x

Salmon, W. C. (1989), Four Decades of Scientific Explanation, Minneapolis: University of Minnesota Press.

Scandellari, C. \& Federspil, G. (1985), Metodologia medica, Roma: Edizioni L. Pozzi. 
Scandellari, C. (2010), 'La metodologia in medicina,' in A. Pagnini (ed.) Filosofia della medicina. Epistemologia, ontologia, etica, diritto, Roma: Carocci, pp. 221-254.

Scriven, M. (1959), 'Explanation and prediction in evolutionary theory', Science, vol. 130, pp. 477-482. https://doi.org/10.1126/science.130.3374.477

Slottje, P.; Sluijs, J. P. van der \& Knol, A. B. (2008), Expert Elicitation: Methodological Suggestions for its Use in Environmental Health Impact Assessment, RIVM letter report $630004001 / 2008$.

Suppes, P. (1970), A Probabilistic Theory of Causality, Amsterdam: North-Holland Publishing Company.

Uffink, J. (1999), 'The principle of the common cause faces the Bernstein paradox,' Philosophy of Science, vol. 66, pp. S512-S525. https://doi.org/10.1086/392749

Zanotti, R., \& Chiffi, D. (2015), 'Diagnostic frameworks and nursing diagnoses: a normative stance,' Nursing Philosophy, vol. 16, no. 1, pp. 64-73.

https://doi.org/10.1111/nup.12074

Pierdaniele Giaretta, PhD, is full Professor of Logic and Philosophy of Science at the Department of Philosophy, Sociology, Education and Applied Psychology, University of Padua. He teaches first-cycle degree in Philosophy, second-cycle degree in Philosophical Sciences, and the PhD program in Philosophy. His main areas of research are philosophy of logic, analytic ontology, and philosophy of medicine.

Daniele Chiff, PhD, is Research Fellow in Philosophy at Tallinn University of Technology. He studied logic, history and philosophy of science in Lecce, Bari, Amsterdam, and Paris. He has been postdoctoral fellow in clinical departments at the University of Padua. His main research interests are (formal) pragmatics, philosophical logics and philosophy of medicine. 